\title{
Neonatal Screening for G6PD, 17-OHP and TSH Levels
}

\author{
Nitin Kadam ${ }^{1}$, Reeta Dhar ${ }^{2}$, Rupinder Deep Kaur Gill ${ }^{3}$ \\ ${ }^{1}$ Professor and Head, Department of Paediatrics, "MGM Medical College, Kamothe", \\ MGM Campus, Sector 1, Kamothe, Navi Mumbai-410209, Maharashtra State (India) \\ ${ }^{2}$ Professor and Head, Department of Pathology, "MGM Medical College, Kamothe", \\ MGM Campus, Sector 1, Kamothe, Navi Mumbai-410209, Maharashtra State (India) \\ ${ }^{3}$ MBBS Undergraduate student, "MGM Medical College, Kamothe", \\ MGM Campus, Sector 1, Kamothe, Navi Mumbai-410209, Maharashtra State (India)
}

\begin{abstract}
Objective: The basic screening of newborn babies for detecting pathologies like G6PD deficiency leading to hyperbilirubinemia, congenital adrenal hyperplasia and congenital hypothyroidism. Method: A Screening Program was conducted at a tertiary care hospital for 2 months i.e. April 2014 to May 2014. All the neonates born in this hospital were screened on third to fifth day oftheir birth for levels of Glucose-6-Phosphate Dehydrogenase (G6PD), 17- Hydroxyprogesterone (17-OHP) and Thyroid Stimulating Hormone (TSH). Results: Out of a total of 57 neonates screened in 2 months, 2 cases $(4.26 \%$, 1 male and 1 female) were observed as G6PD deficient and no cases were observed for increased level 17-OHP and increased level of TSH. Conclusion: Neonatal screening is very important in reducing neonatal mortality and morbidity. Screening programs help us to identify those cases that cannot be identified by routine observation and physical examination. A cost effective nation wide screening program is highly recommended for detection of cases as early as possible.
\end{abstract}

Keywords: Neonatal screening, G6PD, TSH, 17 - OHP

\section{Introduction}

India is currently undergoing an epidemiological transition and congenital malformations and genetic disorders are gradually replacing sepsis as the major cause of perinatal and neonatal mortality[1]. Presently, they constitute the fourth commonest cause $(9.2 \%)$ of neonatal mortality in urban areas [2]. It is not only a leading cause of fetal loss, but also contributes significantly to preterm birth, childhood and adult morbidity along with considerable repercussion on the mothers and their families. This is because consanguineous marriages are still fairly common in many parts of India and these disorders, which were hitherto masked by infections and malnutrition, are being increasingly identified [3],[4].Indian people are living in the midst of risk factors for birth defects, e.g., universality of marriage, high fertility, large number of unplanned pregnancies, poor coverage of antenatal care, poor maternal nutritional status, high consanguineous marriages rate, and high carrier rate for hemoglobinopathies. India being the second most populous country with a large number infant born annually with birth defects should focus its attention on strategies for control of birth defects [5].

According to joint World Health Organization (WHO) and MOD meeting report, birth defects account for $7 \%$ of all neonatal mortality and 3.3 million under five deaths [6]. It has been estimated that $70 \%$ of birth defects are preventable [6].Many population based strategies such as iodization, double fortification of salt, flour fortification with multivitamins, folic acid supplementation, periconceptional care, carrier screening and prenatal screening are some of proven strategies for control of birth defects [5].Neonatal screening is helpful to prevent serious disability and sufferings caused by congenital or inherited disease. Early detection (soon after birth) and an accurate diagnosis are very important for achieving a rapid and favorable patient outcome. Although the incidence of each specific metabolic disorder is rare, their collective importance is deemed to be of considerable public health significance.

This study will be carried out to detect the levels of Glucose6-phosphate dehydrogenase (G6PD), 17Hydroxyprogesterone (17-OHP) and Thyroid-stimulating hormone (TSH) in neonates.

\subsection{Measuring G6PD levels}

One of the most common genetic disorders in Asia is G6PD deficiency[7]. In India, 390,000 children are born annually with this disordercausing significant morbidity and mortality in childhood [8]. Glucose-6-phosphate dehydrogenase (G6PD) is the first enzyme in thepentose phosphate pathway in red blood cells [10]. The mainphysiologic role of this pathway is to generate the reducednicotinamide adenine dinucleotide phosphate (NADPH) necessaryfor protection of the cells against oxidative stress [11]. NADPHmaintains glutathione in the reduced state when erythrocytes aresubjected to an oxidative stress [12]. Low activities of G6PD render redblood cells susceptible to hemolysis under certain conditions such asingestion of fava beans, certain oxidative and anti- malarial drugs, and severe infections like viral hepatitis, pneumonia, and typhoid fever [10]' [13].

G6PD deficiency is one of the most common human enzyme deficiencies, affecting more than 400 million people worldwide [15]. Common clinical manifestations of G6PDdeficient subjects are neonatal jaundice and acute hemolytic anemia. Most people with this disorder are male since the inherited deficiency is an X-linked enzymatic defect. G6PD 


\section{International Journal of Science and Research (IJSR) \\ ISSN (Online): 2319-7064}

Index Copernicus Value (2013): 6.14 | Impact Factor (2014): 5.611

deficiency is the most significant factor that contributes to severe neonatal hyperbilirubinaemia and kernicterus or even death [9].

\subsection{Measuring 17-OHP levels}

17-Hydroxyprogesterone (17-OHP) is a C-21 steroid hormone produced during the synthesis of glucocorticoids and sex corticoids in the adrenal glands. Its measurement is useful in the evaluation of patients with suspected congenital adrenal hyperplasia $(\mathrm{CAH})$ as the typical enzymes that are defective, namely 21 -hydroxylase and $11 \beta$ hydroxylase, lead to a build-up of 17-OHP [14].

Congenital adrenal hyperplasia $(\mathrm{CAH})$ is a recessively inherited disorder, which occurs in 1:16,000-1:20,000 births [18]. More than $90 \%$ of all cases of CAH are caused by $21-$ hydroxylase deficiency[16]. This enzyme deficiency results in a reduced ability to synthesize cortisol and aldosterone and an increased secretion of androgens.

There is a wide spectrum of severity of CAH [16]' [17]. Historically, the patients have been classified according to their salt-losing tendency. The most severe forms lead to a salt-wasting (SW) crisis, usually during the first weeks of life, as a result of a severe lack of both glucocorticoids and mineralocorticoids. The elevated androgen levels during embryogenesis cause virilization of the external genitalia in girls with $\mathrm{CAH}$ : clitoromegaly, fusion of the labia majora, and a common urethral and vaginal opening. A less severe form of 21- hydroxylase deficiency, with pre-natal virilization but without life- threatening salt loss, usually is referred to as the simple virilizing (SV) form of $\mathrm{CAH}$.

\subsection{Measuring TSH levels}

Thyroid Stimulating Hormone (TSH) is a glycoprotein produced in the anterior lobe of the pituitary gland. TSH is carried by the bloodstream to the thyroid gland where it stimulates the synthesis and secretion of the thyroid hormones triiodothyronine (T3) and thyroxine (T4). An increase in TSH above the normal range indicates Congenital Hypothyroidism $(\mathrm{CH})$.

Congenital Hypothyroidism $(\mathrm{CH})$ occurs in approximately 1:4000 newborns [19]. Congenital hypothyroidism occurs when the thyroid gland fails to develop or function properly. In 80 to 85 percent of cases, the thyroid gland is absent, abnormally located, or severely reduced in size (hypoplastic). In the remaining cases, a normal-sized or enlarged thyroid gland is present, but production of thyroid hormones is decreased or absent. Confirmation of hypothyroidism should be performed by using serum T3, T4 and TSH determinations prior to initiating therapy. If untreated, congenital hypothyroidism can lead to intellectual disability and abnormal growth.

\section{Literature Survey}

A lot of articles have been published all over the world on neonatal screening. Some of them are listed below:
A study by Rama Devi AR et al.[20] was the first expanded NBS programme initiated in the capital city of Andhra Pradesh to screen all the newborns born in four major Government Maternity Hospitals in Hyderabad by heel prick capillary blood collected on S\&S 903 filter paper. Chromatographic (TLC and HPLC), electrophoretic (cellulose acetate and agarose) and ELISA based assays have been employed for screening of common inborn errors of metabolism. This study has shown a high prevalence of treatable inborn errors of metabolism. Congenital hypothyroidsm is the most common disorder (1 in 1700) followed by congenital Adrenal Hyperplasia (1 in 2575) and Hyperhomocystenemia ( 1 in 100). Interestingly, a very high prevalence of inborn errors of metabolism to the extent of 1 in every thousand newborns was observed. The study reveals the importance of screening in India, necessitating nation wide large-scale screening.

Anotherstudy by MritunjayPao et al. [21] was carried out to detect the incidence of erythrocytic Glucose-6-Phosphate dehydrogenase (G-6-PD) deficiency, to compare the incidence of hyperbilirubinernia in G-6-PD deficient neonates as compared to G-6-PD normal neonates and to assess the usefulness of neonatal screening for G-6-PD deficiency.Incidence of G-6-PD deficiency was found to be $2.0 \%$. Incidence in males was $283 \%$ and femle was $1.05 \%$. The incidence of hyperbilirubinemia was found to be $32 \%$ in G-6-PD deficient neonates, which was significantly higher than the incidence of hyperbilirubinemia in neonates with normal G-6-PD, which was $12.3 \%(\mathrm{P}<0.001)$. Their data suggests that neonatal screening for G-6-PD deficiency is a useful test for preventing and early treatment of complications associated with it.

A preliminary study by GurjitKauret al. [22] was carried for newborn screening of three disorders namely, congenital hypothyroidism, congenital adrenal hyperplasia and glucose6-phosphate dehydrogenase deficiency and to establish newborn screening in Indian scenario that could lay a framework for future such initiatives. Six thousand eight hundred and thirteen $(6,813)$ neonates $(86.3 \%)$, out of a total of 7,893 live births in our institute during the period May'2007 through July'2009, were screened for CAH, CH andG6PD deficiency. G-6-PD deficiency was confirmed in 61 cases, congenital hypothyroidism $(\mathrm{CH})$ in 2 cases and congenital adrenal hyperplasia $(\mathrm{CAH})$ in 1 neonate, accounting for an incidence of 1/112 for G-6-PDD, 1/ 3400 for $\mathrm{CH}$ and $1 / 6813$ for $\mathrm{CAH}$. They concluded that preliminary data on prevalence of various genetic disorders viz. G-6-PDD, $\mathrm{CH}$ and $\mathrm{CAH}$ in the population of this region revealed that G-6-PDD is most prevalent disorder followed by $\mathrm{CH}$ and $\mathrm{CAH}$. More efforts need to be undertaken to create awareness and emphasis on significance of preventive testing to make screening a successful program in India.

Anotherstudy was done by Mohammad Hussain et al.[23] to detect the frequency of G-6-PD deficiency in 200 consecutive neonates admitted with jaundice to the neonatal unit, LRH, Peshawar. Out of the 200 icteric neonates, 145 $(72.5 \%)$ were males while $55(27.5 \%)$ were females. Thirtytwo (16\%) babies were found to be G-6-PD deficient. 


\section{International Journal of Science and Research (IJSR) \\ ISSN (Online): 2319-7064}

Index Copernicus Value (2013): 6.14 | Impact Factor (2014): 5.611

Anotherstudy was done by Mohammad Najafi et al.[24] to estimate the incidence of neonatal hypothyroidism and assessment of iodine deficiency in the eastern part of Iran. In the study, the recall rate and incidence of hypothyroidism were $3.6 \%$ and 2 per 1000 neonates respectively. They concluded that a comprehensive policy should be developed for control of iodine deficiency and treatment of hypothyroidism in the studied population and neighboring countries.

Anotherstudy was done by SinanMahirKayıran et al.[25] for correlation of third day TSH and thyroxine values with bilirubin levels detected by a neonatal screening system. For the purpose of screening for congenital hypothyroidism and metabolic diseases blood is drawn for analysis from all newborns about 72 hours of postnatal age, which coincides with the approximate peak-time of bilirubin levels. Adding the measurement of serum bilirubin concentrations to the blood tests in programs of this kind will serve to detect high levels of bilirubin. The study was designed to investigate a relationship, between neonatal $\mathrm{TSH}, \mathrm{T} 4$ and total bilirubin levels in the blood samples of postnatal third day. Their results suggest that simultaneously measurement of T4, TSH, and bilirubin levels is a useful clinical tool for screening but there seems to be no significant clinical correlation between these parameters in healthy term newborns.

Another study was done by Jian-Ying Zhan et al. [26] to review the status of neonatal screening for congenital hypothyroidism $(\mathrm{CH})$ and phenylketonuria (PKU) in China. Of 18.8 million newborns screened from 1985 to 2007, 9198 were identified with $\mathrm{CH}$, giving a prevalence of $1 / 2047$. In 19.0 million newborns screened in the same period, 1638 had PKU, with a prevalence of 1/11 572 . Confirmatory tests were performed and treatments were initiated in most of the neonates with $\mathrm{CH}$ and PKU within a month after birth. The study concluded that more governmental support at different levels is needed to make neonatal screening more efficient. The screening should be improved with a satisfactory control system including shorter time of report and a higher recall rate.

An article by Harish Nair[27] emphasized on the need for a National Neonatal Screening program for presumptive screening of all neonates for Glucose-6-phosphate dehydrogenase (G6PD) deficiency. It also provided funding options like National Rural Health Mission.

All the studies mentioned above, depicts screening programs for G6PD, 17-OHP and TSH conducted at small scales through out the world, indicating their prevalence. They all indicate the need of a nation wide cost effective screening program.

\section{Material and Methods}

\subsection{Material}

- The Quantase Neonatal G6PD Deficiency Screening Assay Kit

- $\quad$ The Quantase Neonatal 17-OHP Screening Assay Kit

- The Quantase Neonatal TSH Screening Assay Kit

- Quantase Neonatal Accessory Kit Assay Plates
- Repeating or multi-channel pipettes

- Plate Shaker

- Plate reader with $450 ; 630$ or 690 and $550-570 \mathrm{~nm}$ filter

- $\quad 1 / 8 "(3.2 \mathrm{~mm})$ diameter Puncher

- Round bottom microtitre plates

- Plate washer or manual plate washing equipment
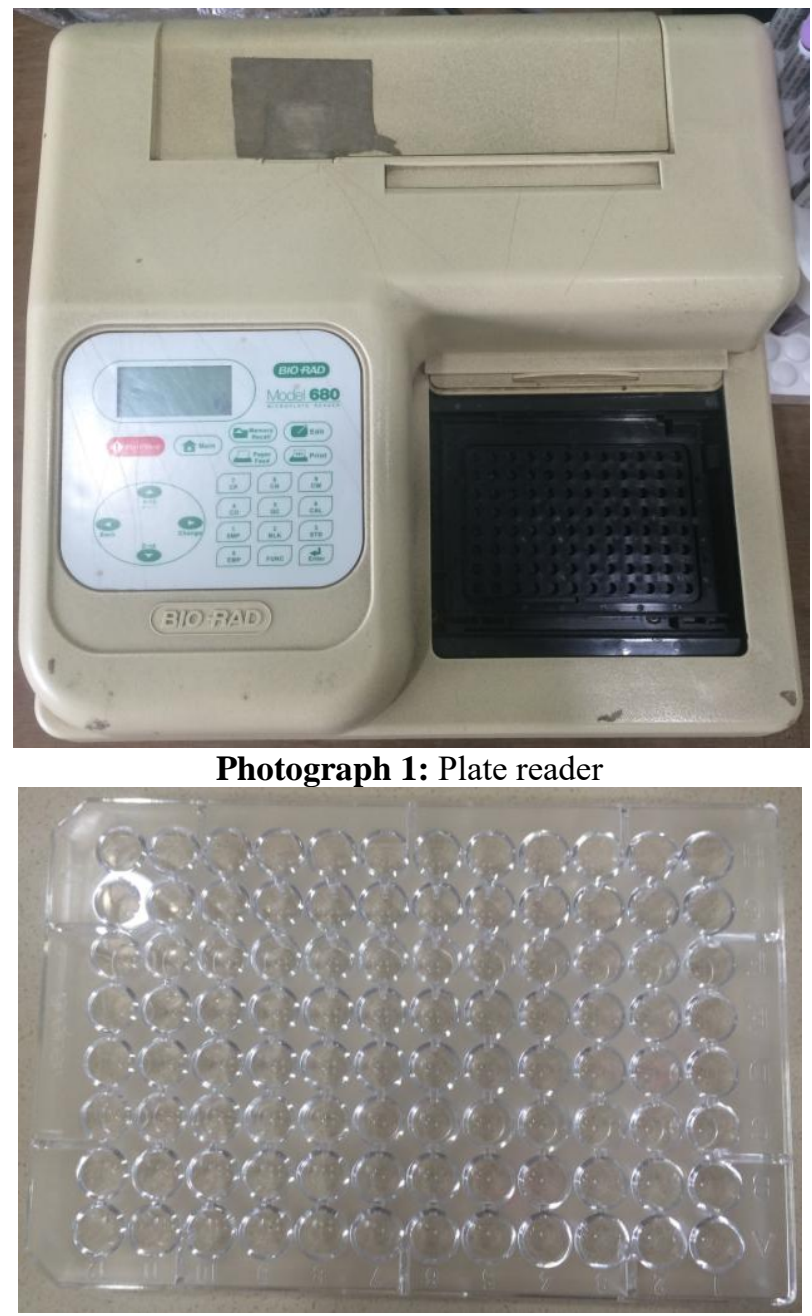

Photograph 2: Round bottom microtitre plates

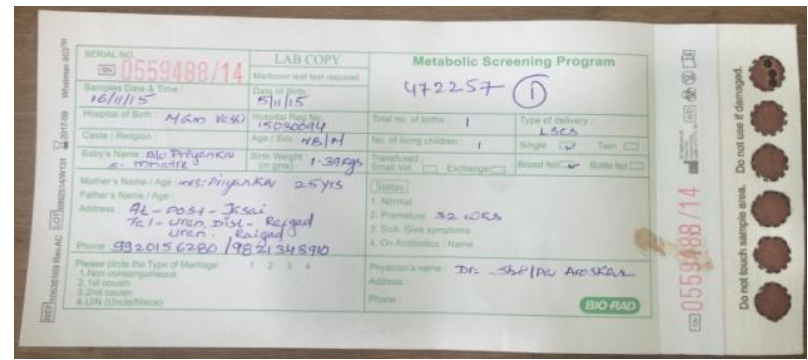

Photograph 3: Specimen collection paper

Study Design: Prospective study

Study Centre: Pathology Department, MGM Medical College, Kamothe.

Study Duration: 2 months

Study Population: Neonates between third and fifth day of life (48 to 120 hours) after birth.

Sample size: 47 patients

Inclusion criteria: All neonates

Exclusion criteria: None 


\section{International Journal of Science and Research (IJSR) \\ ISSN (Online): 2319-7064}

Index Copernicus Value (2013): 6.14 | Impact Factor (2014): 5.611

Data Collection Procedure: For collection of the blood, the heel prick method was used.

\subsection{Principle of the Procedure}

\subsubsection{For G6PD levels}

The Quantase Neonatal G6PD Deficiency Screening Assay is a rapid, colorimetric assay for the quantitative determination of G6PD activity in dried blood spot specimens collected on Schleicher and Schuell (S\&S) 903 specimen collection paper. It utilizes the dried blood spot specimens (DBS) eluted in a buffered solution. An aliquot of the elute is incubated with a solution containing G6PD, NADP+ and a tetrazolium salt. G6PD present in the specimen converts NADP+ to NADPH. The tetrazolium salt is converted to a colouredformazandye, which is detected by a kinetic reading $(\mathrm{OD} / \mathrm{min})$ at 550 or $570 \mathrm{~nm}$. G6PD activity, in units/gmhaemoglobin, is calculated by multiplying the rate in $\mathrm{mOD} / \mathrm{min}$ by a Factor. The Factor is obtained by dividing the known value of the Normal Control by the rate of the Normal Control. One unit is defined as the quantity of G6PD, which catalyzes the formation of $1 \mu$ mole of NADPH per minute per gram of haemoglobin.

\subsubsection{For 17-OHP levels,}

The Quantase Neonatal 17-OHP Screening Assay is a quantitative assay for the determination of 17-OHP in neonatal dried blood spot specimens collected on Schleicher and Schuell (S\&S) 903 specimen collection paper. It is a competitive enzyme - immunoassay (EIA). Dried blood spot specimens are eluted directly into anti- rabbit IgG antibody coated microwells in a solution containing peroxidase labeled 17-OHP and anti - 17- OHP antibody. After incubation, the wells are washed free of unbound labeled 17OHP and antibody. Bound 17- OHP in the specimen is determined by the reaction of bound peroxidase - labeled 17OHP with substrate with the generation of a coloured product. Because of the competition between 17-OHP in the specimen and enzyme - labeled 17-OHP, the colour generated is inversely proportional to the concentration of $17-\mathrm{OHP}$ in the specimen. Values are expressed as $\mathrm{ng} / \mathrm{ml}$ whole blood.

\subsubsection{For TSH levels,}

The Quantase Neonatal TSH Screening Assay is a quantitative assay for the determination of TSH in neonatal dried blood spot specimens collected on Schleicher and Schuell (S\&S) 903 specimen collection paper. This test is intended as a screening method for the measurement of TSH concentrations in newborn blood spot specimens as an aid to the diagnosis of Congenital Hypothyroidism. The sample is incubated with a peroxidase - labeled anti - TSH antibody (Conjugate Reagent) in a microwell coated with another anti - TSH monoclonal antibody. After incubation, the wells are washed free of unbound labeled antibody. TSH in the sample is determined by the reaction of the bound Conjugate with Substrate producing a coloured product. The concentration of $\mathrm{TSH}$ in the sample is proportional to colour measured at $450 \mathrm{~nm}$ in a plate reader. TSH concentrations are expressed as $\mu \mathrm{l} \mathrm{U} / \mathrm{ml}$ whole blood.

\subsection{Preparation of Reagents and Storage}

3.3.1. ForG6PDlevelcalculation,

(a) Coenzyme Reagent

- Reconstitute the Coenzyme Reagent with the Buffered Substrate vial into the vial containing the lyophilized Coenzyme Reagent. Swirl gently to aid reconstitution.

- Reconstituted Coenzyme Reagent is stable for 30 days at $2-8^{\circ} \mathrm{C}$.

(b) Working Reagent

- Prepare the working reagent by mixing equal volumes of the Colour Reagent and reconstituted Coenzyme Reagent. Each specimen or control to be tested requires $100 \mu \mathrm{L}$ of Working Reagent. Swirl gently to mix.

- The Working Reagent is stable for 3 days at $2-8^{\circ} \mathrm{C}$.

- Do not mix stored and fresh Working Reagents together.

- All reagents should be equilibrated to room temperature $\left(18-25^{\circ} \mathrm{C}\right)$ before use.

- $\quad$ Store all liquid reagents at $2-8^{\circ} \mathrm{C}$.

- Store Blood Spot Controls at $-20^{\circ} \mathrm{C}$.

\subsubsection{For17-OHPandTSHlevelcalculation,}

- All the reagents in this kit are ready to use except for the Wash Buffer.

- Wash Buffer: Prepare the Wash Buffer by mixing 1 bottle of 20x Wash Buffer Concentrate with $1900 \mathrm{~mL}$ of deionized water.

- The diluted (1x) Wash Buffer is stable for 60 days at ambient temperature $\left(18-25^{\circ} \mathrm{C}\right)$.

- Equilibrate all kit components to ambient temperature $\left(18-25^{\circ} \mathrm{C}\right)$ before use.

- Store all reagents in the Quantase Neonatal 17-OHP Screening Assay kit at $2-8{ }^{\circ} \mathrm{C}$ until kit expiration.

- Unused Coated Reaction Well strips should be stored in the pouch sealed with desiccant at $2-8{ }^{\circ} \mathrm{C}$.

\subsection{Procedure}

\subsubsection{ForG6PDlevelcalculation}

(a) Elution

- Punch one 1/8" diameter disc from the Blood Spot Controls into a round-bottomed microtitre plate. Punch patient specimens into the remaining wells of the plate, noting their position. Blood Spot Controls should be punched in duplicate.

- Pipette $200 \mu \mathrm{L}$ of Elution Buffer into each well and incubate at room temperature $\left(18-37^{\circ} \mathrm{C}\right)$ with gently shaking for 20 minutes. Ensure that each disc is fully immersed in the Elution Buffer.

(b) Sample transfer/ Colour Generation

- After the 20-minute incubation period, remove the plate from the plate shaker. Use a multi- channel pipette to mix and transfer $100 \mu \mathrm{L}$ of the elute into a flat bottomed microtitre plate (Assay Plate).

- $\quad$ Pipette $100 \mu \mathrm{L}$ of Working Reagent into each well and mix gently. Place the plate in the plate reader and read the absorbance of the plate at 550 or $570 \mathrm{~nm}$ (Initial Reading).

- Incubate the plate for 10 minutes at room temperature $\left(18-37^{\circ} \mathrm{C}\right)$, with no shaking.

- Read the absorbance of the plate at 550 or $570 \mathrm{~nm}$ (Final Reading). 


\section{International Journal of Science and Research (IJSR) \\ ISSN (Online): 2319-7064}

Index Copernicus Value (2013): 6.14 | Impact Factor (2014): 5.611

3.4.2. For17-OHPlevelcalculation,

(a) Punch $1 \mathrm{x} 1 / 8 "(3.2 \mathrm{~mm})$ diameter disc from each Standard and Control or patient specimen into the wells of the Coated Reaction strips. Standards must be punched in duplicate.

(b) Add $50 \mu \mathrm{L}$ of Conjugate Reagent and $50 \mu \mathrm{L}$ of Antibody Reagent to all wells containing Standards, Controls and patient specimens.

(c) Incubate the microtitre plate for 5 minutes at ambient temperature $\left(18-25^{\circ} \mathrm{C}\right)$ without shaking.

(d) Place the microtitre plate on the plate shaker and incubate at ambient temperature $\left(18-25^{\circ} \mathrm{C}\right)$ for 30 minutes at $600 \mathrm{rpm}$ followed by 3 hours at $300 \mathrm{rpm}$ ensuring that all punched discs are immersed in the Reagents throughout.

(e) For manual plate washing, decant the contents of the wells, including the punched discs into a suitable disinfectant - containing waste container. Wash the plate with a plate washer 5 times using a minimum of $300 \mu \mathrm{L}$ Wash Solution per well. After the last wash, firmly tap the plate on absorbent paper to remove any residual Wash Solution. When an automated plate washer is used, follow the manufacturer's instructions to wash the plate 5 times using a minimum of $300 \mu \mathrm{L}$ Wash Solution per well. After the last wash, firmly tap the plate on absorbent paper to remove any residual Wash Solution.

(f) Add $100 \mu \mathrm{L}$ of Substrate Reagent to all wells. Place the microtitre plate on the plate shaker and incubate at ambient temperature $\left(18-25^{\circ} \mathrm{C}\right)$ for 30 minutes at 300 rpm.

(g) Add $100 \mu \mathrm{L}$ of Stop Reagent to all wells. Gently mix the plate contents by tapping the plate.

(h) Read the absorbance of the plate within 30 minutes of Stop Reagent addition at $450 \mathrm{~nm}$ in single wavelength mode or $450 / 630$ or $450 / 690 \mathrm{~nm}$ in dual wavelength mode.

\subsubsection{ForTSHlevelcalculation}

(a) Punch $1 \times 1 / 8$ " (3.2mm) diameter disc from each Standard and Control or patient specimen into the wells of the Coated Reaction strips. Standards must be punched in duplicate.

(b) Add $100 \mu \mathrm{L}$ of Conjugate Reagent to all wells containing Standards, Controls and patient specimens.

(c) Incubate the microtitre plate for 5 minutes at ambient temperature $\left(18-25^{\circ} \mathrm{C}\right)$ without shaking.

(d) Place the microtitre plate on the plate shaker and incubate at ambient temperature $\left(18-25^{\circ} \mathrm{C}\right)$ for 30 minutes at $600 \mathrm{rpm}$ followed by 3 hours at $300 \mathrm{rpm}$ ensuring that all punched discs are immersed in the Reagents throughout.

(e) For manual plate washing, decant the contents of the wells, including the punched discs into a suitable disinfectant - containing waste container. Wash the plate with a plate washer 5 times using a minimum of $300 \mu \mathrm{L}$ Wash Solution per well. After the last wash, firmly tap the plate on absorbent paper to remove any residual Wash Solution. When an automated plate washer is used, follow the manufacturer's instructions to wash the plate 5 times using a minimum of $300 \mu \mathrm{L}$ Wash Solution per well. After the last wash, firmly tap the plate on absorbent paper to remove any residual Wash Solution.

(f) Add $100 \mu \mathrm{L}$ of Substrate Reagent to all wells. Place the microtitre plate on the plate shaker and incubate at ambient temperature $\left(18-25^{\circ} \mathrm{C}\right)$ for 30 minutes at 300 rpm.

(g) Add $100 \mu \mathrm{L}$ of Stop Reagent to all wells. Gently mix the plate contents by tapping the plate.

(h) Read the absorbance of the plate within 30 minutes of Stop Reagent addition at $450 \mathrm{~nm}$ in single wavelength mode or $450 / 630$ or $450 / 690 \mathrm{~nm}$ in dual wavelength mode.

Quality control: Each assay will include the Normal and Abnormal Controls.

\subsection{Statistical Tools}

\subsubsection{For G6PD level calculation,}

The rates $(\mathrm{mOD} / \mathrm{min})$ of the patient specimens are calculated as follows:

$$
\mathrm{mOD} / \min =\frac{\text { Final } O D-\text { Initial } O D}{10}
$$

The G6PD activity of the patient specimens is calculated by comparing the rates of the patient specimens to rate of the Normal Control, which has known G6PD activity. The G6PD activity of the patient specimens is calculated by multiplying the rate for the specimen by the Factor, which is already mentioned in the kit.

$$
\begin{aligned}
& \text { Specimen Activity }(U / g \mathrm{Hb}) \\
& =\text { Rate }\left(\mathrm{mOD} / \mathrm{min}_{\min }\right) \times \text { Factor }
\end{aligned}
$$

\subsubsection{For 17-OHP and TSH level calculation,}

Use a 4-parameter logistic (4PL) curve fit for the Standard Curve and for calculating results.

Ethical Approval: This study was approved by the Institutional Ethics Committee (IEC)

\section{Results}

Table 1: Neonatal G6PD

\begin{tabular}{|c|c|c|c|c|}
\hline $\begin{array}{c}\text { Neonatal } \\
\text { G6PD }\end{array}$ & $\begin{array}{c}\text { Normal } \\
(>2.0)\end{array}$ & $\begin{array}{c}\text { Intermediate } \\
(1.5-2.0)\end{array}$ & $\begin{array}{c}\text { Abnormal } \\
(<1.5)\end{array}$ & Total \\
\hline Male & $26(96.30 \%)$ & $0(0 \%)$ & $1(3.70 \%)$ & $27(57.45 \%)$ \\
\hline Female & $19(95 \%)$ & $0(0 \%)$ & $1(5 \%)$ & $20(42.55 \%)$ \\
\hline Total & $45(95.74 \%)$ & $0(0 \%)$ & $2(4.26 \%)$ & $47(100 \%)$ \\
\hline
\end{tabular}

Table 2: Neonatal 17-OHP

\begin{tabular}{|c|c|c|c|c|}
\hline $\begin{array}{c}\text { Neonatal } \\
\text { 17-OHP }\end{array}$ & $\begin{array}{c}\text { Normal } \\
(<100)\end{array}$ & $\begin{array}{c}\text { Equivocal } \\
(100-149)\end{array}$ & $\begin{array}{c}\text { Positive } \\
(>150)\end{array}$ & Total \\
\hline Male & $27(57.45 \%)$ & $0(0 \%)$ & $0(0 \%)$ & $27(57.45 \%)$ \\
\hline Female & $20(42.55 \%)$ & $0(0 \%)$ & $0(0 \%)$ & $20(42.55 \%)$ \\
\hline Total & $47(100 \%)$ & $0(0 \%)$ & $0(0 \%)$ & $47(100 \%)$ \\
\hline
\end{tabular}

Table 3: Neonatal TSH

\begin{tabular}{|c|c|c|c|c|}
\hline $\begin{array}{c}\text { Neonatal } \\
\text { TSH }\end{array}$ & $\begin{array}{c}\text { Normal } \\
(0-10)\end{array}$ & $\begin{array}{c}\text { Borderline } \\
(10-20)\end{array}$ & $\begin{array}{c}\text { Abnormal } \\
(>20)\end{array}$ & Total \\
\hline Male & $27(57.45 \%)$ & $0(0 \%)$ & $0(0 \%)$ & $27(57.45 \%)$ \\
\hline Female & $20(42.55 \%)$ & $0(0 \%)$ & $0(0 \%)$ & $20(42.55 \%)$ \\
\hline Total & $47(100 \%)$ & $0(0 \%)$ & $0(0 \%)$ & $47(100 \%)$ \\
\hline
\end{tabular}




\section{International Journal of Science and Research (IJSR) \\ ISSN (Online): 2319-7064}

Index Copernicus Value (2013): 6.14 | Impact Factor (2014): 5.611

Table 4: Summary

\begin{tabular}{|c|c|c|}
\hline & Number & Percentage \\
\hline Total number of neonates & 47 & $100 \%$ \\
\hline Number of males & 27 & $57.45 \%$ \\
\hline Number of females & 20 & $42.55 \%$ \\
\hline G6PD deficit cases & 2 & $4.26 \%$ \\
\hline High 17-OHP cases & 0 & $0 \%$ \\
\hline High TSH cases & 0 & $0 \%$ \\
\hline
\end{tabular}

Out of a total of 57 neonates screened in 2 months, 2 cases (4.26\%, 1 male and 1 female) were observed as G6PD deficient and no cases were observed for increased level 17$\mathrm{OHP}$ and increased level of TSH.

\section{Conclusion}

This study emphasized on the screening of G6PD, 17-OHP and TSH in neonates in a tertiary care hospital during the period of April 2014 to May 2014.

\subsection{G6PD}

Early detection of G6PD deficiency by neonatal screening will prevent the following manifestations in the neonates: hyperbilirubinemia/ kernicterus or even haemolyticanaemia in future life. Therefore the study will help in prior intimation to the consulting physician for taking precautions in prescribing the drugs to deficient individuals suffering from viral hepatitis, pneumonia, typhoid fever and malaria.

\subsection{7-OHP}

This screening will aid to the diagnosis of Congenital Adrenal Hyperplasia (CAH).

\subsection{TSH}

Congenital hypothyroidism will be detected by this screening assay to cure and treat the disease at an early stage and thus prevent mental retardation in children.

Out of the 47 screened neonates, 2 cases were observed as G6PD deficient, depicting an incidence of $4.26 \%$. Tertiary care hospital usually do not have definite catchment area and complicated cases are more commonly encountered. Hence, prevalence calculated in this type of hospital-based study cannot be projected to the total population.

In conclusion, neonatal screening is crucial in early detection of various congenital disorders and prevention of neonatal mortality and morbidity. More governmental support at different levels is needed to make neonatal screening as a cost effective national network, which covers neonates throughout the country in the screening program and leads to awareness and detection of cases as early as possible and treating cases at the earliest particularly hypothyroidism.

\section{Future scope:}

Screening approach varies in different regions due to different socioeconomic status. Multi-centralized screening approach with multi-centers in charge of the local neonatal screening requires more investment in laboratory equipment and staffing, compared with the centralized provincial screening approach. The quality of multi- centralized screening is seriously affected by technical and medical limitations as well as difficulty in quality control across different laboratories and regions. It is probably more efficient to send the blood sample to the nearest large testing center and then give the results back to the local units rather than having many small local laboratories testing samples. It is of critical importance to build a provincial or national network to include the newborns in those regions not covered by the neonatal screening, so as to ensure the possibility of early detection of cases.

Neonatal screening is a multidisciplinary program that requires a close coordination of health administration, screening centers, hospitals, laboratories and parents of the children to ensure high recall rates of suspected cases and timely therapy. Parental compliance is a major issue in screening since some parents still do not understand the necessity to treat and follow up their health-looking neonates, and fail to return for further diagnosis or treatment.

Neonatal screening evolves and its spectrum broadens because new technical and analytical methods are available. Internationally, it is performed with sensitive and reliable tandem mass spectrograph for more than 30 inheritable metabolic diseases, including abnormalities in the metabolism of amino acids, fatty acids and organic acids.

Neonatal screening in India has been improved in the last 20 years. Many areas still need to be improved, including establishment of an efficient quality control system, an efficient system for recall, initiating treatment and follow-up, and a cost-effective screening model.

Screening programs help us to identify those individuals who cannot be identified by routine observation and physical examination. Indeed, in India, only $32 \%$ of the G6PD deficient neonates had hyperbilirubinemia and $55 \%$ of the G6PD deficient newborns did not require phototherapy. This implies that without a newborn screening program to identify the G6PD deficient newborns, these infants run a greater risk of unexpected hemolytic anaemia if exposed to triggers. However, neonates with elevated TSH levels have a prevalence of 1 in 4000. Congenital TSH and growth hormone deficiencies may occur as a result of a difficult birth or anoxia. Early detection of congenital hypothyroidism can prevent mental and growth retardation. If treated early, there are only minor differences in intelligence, school achievement, and neuropsychological testing between normal and treated patients.

More governmental support at different levels is needed to make neonatal screening more efficient. The screening should be improved with a satisfactory control system including shorter time of report and a higher recall rate.

\section{References}

[1] Mohanty C, Mishra OP, Das BK, Bhatia BD, Singh G. Congenital malformations in newborns: A study of 10,874 consecutive births. J AnatSoc India. 1989;38:101-11. 


\section{International Journal of Science and Research (IJSR) \\ ISSN (Online): 2319-7064}

Index Copernicus Value (2013): 6.14 | Impact Factor (2014): 5.611

[2] National Neonatology Forum. National NeonatalPerinatal Database (2002-03). Delhi: NNPD Nodal Centre, AIIMS; 2005. Available from: http:// www.nnfi.org/images/NNPD_2002-03.pdf Accessed 12 March, 2008.

[3] Nair H. Neonatal screening program for G6PD deficiency in India: need and feasibility. Indian Pediatr. 2009 Dec;46(12):1045-9.

[4] Nair H. Neonatal screening program for G6PD deficiency in India: need and feasibility. Indian Pediatr. 2009 Dec;46(12):1045-9.

[5] Rinku Sharma. Birth defects in India: Hidden truth, need for urgent attention. Indian J Hum Genet. 2013 Apr-Jun; 19(2): $125-129$

[6] World health organization. Management of birth defects and haemoglobin disorders: Report of a Joint WHOMarch of Dimes meeting. Geneva, Switzerland, Geneva: WHO; 2006

[7] Panich V. In: Glucose-6-Phosphate Dehydrogenase. Yoshida A and Beutler E. 1986

[8] Verma IC, Bijarnia S. The burden of genetic disorders in India and a framework for community control. Community Genet 2002; 5: 192-196.

[9] Yeung C.Y. Hong Kong Jour. Parediatri. 1992. 9 23350.

[10] Kwok CJ, Martin AC, Au SW, Lam VM. G6PDdb, an integrated database of glucose-6-phosphate dehydrogenase (G6PD) mutations. Hum Mutat. 2002;19(3):217-24. DOI: 10.1002/humu.10036 Mohanty C, Mishra OP, Das BK, Bhatia BD, Singh G. Congenital malformations in newborns: A study of 10,874 consecutive births. J AnatSoc India. 1989;38:101-11. Hudgins L, Cassidy SB. Congenital anomalies. In: Martin RJ, Fanaroff AA, Walsh MC, editors.NeonatalPerinatal Medicine. $8^{\text {th }}$ ed. Philadelphia: MosbyElsevier; 2006. pp. 561-81.

[11] Jablonska-Skwiecinska E, Lewandowska I, Plochocka D, Topczewski J, Zimowski JG, Klopocka J, Burzynska B. Several mutations including two novel mutations of the glucose-6- phosphate dehydrogenase gene in Polish G6PD deficient subjects with chronic nonspherocytic hemolytic anemia, acute hemolytic anemia, and favism. Hum Mutat. 1999;14(6):477-84. DOI: 10.1002/(SICI)1098-1004(199912)14:6<477::AIDHUMU6>3.0.CO;2-X

[12] Gaetani GF, Rolfo M, Arena S, Mangerini R, Meloni GF, Ferraris AM. Active Involvement of Catalase During Hemolytic Crises of Favism. Blood. 1996;88(3):1084-8.

[13] Lim F, Vulliamy T, Abdalla SH. An Ashkenazi Jewish woman presenting with favism. J ClinPathol. 2005;58(3):317-9. DOI: 10.1136/jcp.2004.017426

[14]Donohue P A. et al (1995) in: The Metabolic and Molecular Bases of Inherited Disease 7th Edition (Scriver C R. et al eds.) McGraw Hill, New York, pp. 2929.

[15] World Health Organization. Report of the Working Group- Glucose-6-Phosphate Dehydrogenase Deficiency. Bull World Health Organ 1989; 67: 601611.
[16] White P, Speiser P. Congenital adrenal hyperplasia due to 21- hydroxylase deficiency. Endocrinol Rev. 2000;21:245-291

[17] New MI. Basic and clinical aspects of congenital adrenal hyperplasia. Steroid Biochem. 1987;27:1-7

[18] White PC. Neonatal screening for congenital adrenal hyperplasia. Nat Rev Endocrinol. 2009 Sep;5(9):490-8. doi: $10.1038 /$ nrendo.2009.148.

[19] American Academy of Pediatrics. (1993) Pediatrics 91 1203 - 1209.

[20] Rama Devi AR, Naushad SM.Newborn screening in India. Indian J Pediatr. 2004 Feb;71(2):157-60.

[21] TheIndianJournalofPediatrics October 2005, Volume 72, Issue 10, pp 835-837. Neonatal screening for Glucose-6Phosphate dehydrogenase deficiency.MritunjayPao, Anjali Kulkarni, Vidya Gupta, SushmaKaul, SarojaBalan

[22] TheIndianJournalofPediatrics September 2010, Volume 77, Issue 9, pp 969-973 Date: 27 Aug 2010

Preliminary Report on Neonatal Screening for Congenital Hypothyroidism, Congenital Adrenal Hyperplasia and Glucose-6-Phosphate Dehydrogenase Deficiency: A Chandigarh Experience

GurjitKaur, JyotiSrivastav, Suksham Jain, Deepak Chawla, Bir S. Chavan, Rajiv Atwal, GurpreetRandhawa, AvneetKaur, Rajendra Prasad

[23] Journal of Postgraduate Medical Institute 2010 Volume 24 No. 02 : 122 -126 Glucose-6-Phosphate Dehydrogenase Deficiency in Jaundiced Neonates Mohammad Hussain, Mohammad Irshad, Musa Kalim, Liaqat Ali, Liaqat Ali

[24] IndianJournalofMedicalSciences Vol. 62, No. 3, March 2008 Neonatal Thyroid Screening in a Mild Iodine Deficiency Endemic Area in Iran MohammadNajafi, GholamHosseinKhodaee, MohammadBahari, MasoumehSabahi, MostafaMazlom Farsi, FatomehKiani [25] MedicalJournalofBakırköy, Volume 6, Number 3, 2010 Correlation of Third Day TSH and Thyroxine Values with Bilirubin Levels Detected by a Neonatal Screening System SinanMahirKayıran, BerkanGürakan

[26] WorldJPediatr2009;5(2):136-139 Neonatal screening for congenital hypothyroidism and phenylketonuria in China Jian-Ying Zhan, Yu-Feng Qin, Zheng-Yan Zhao Hangzhou, China

[27]Indian Paediatrics Volume 46-December17,2009 Neonatal Screening Program for G6PD Deficiency in India: Need and Feasibility Harish Nair

\section{Author Profile}

Rupinder deep kaur Gill Pursuing Bachelor of Medicine \& Bachelor of Surgery (MBBS) in MGM Institute of Health Sciences, Kamothe, Navi Mumbai.

Dr. ReetaDhar professor and Head of Department of Pathology. Specialised in reporting histopathology, cytology, haematology and clinical pathology. 25 years of teaching experience for MBBS and 10 years for post graduate teaching (MD Pathology).

Dr Nitin Kadam professor and Head Department of Paediatrics in MGM Institute of Health Sciences, Kamothe, Navi Mumbai. 20 years of teaching experience for MBBS students and 8 years for PG students. 